\title{
A Mixed-Method Study of Same-Sex Kissing Among College-Attending Heterosexual Men in the U.S.
}

\author{
Eric Anderson ${ }^{1} \cdot$ Matthew Ripley ${ }^{2} \cdot$ Mark McCormack $^{3}$
}

Published online: 5 September 2018

(c) The Author(s) 2018

\begin{abstract}
This is the first research to assess the prevalence of same-sex kissing among collegeattending, heterosexual men in the United States. We utilized a mixed-method study of 442 quantitative surveys and 75 in-depth interviews with participants from 11 universities in order to understand the frequency, context and meanings of same-sex kissing. We found that the prevalence of kissing on the cheek among these participants was $40 \%$, and kissing on the lips $10 \%$. Both types of kisses were predicted by positive attitudes toward gay men and both types of kissing were generally described as non-sexual expressions of affection. We situate these empirical results within contemporary theoretical debates about masculinities and contend that the meanings associated with heterosexual masculinity are undergoing a profound shift in U.S. culture. This trend of same-sex kissing needs further attention to fully understand these shifts and the emerging homosocial and tactile experiences of young American men.
\end{abstract}

Keywords Heterosexuality $\cdot$ Kissing $\cdot$ Men $\cdot$ Homosociality

Mark McCormack

markmccormackphd@gmail.com

Eric Anderson

Professorericanderson@gmail.com

Matthew Ripley

matthewripley1989@gmail.com

1 University of Winchester, Winchester, UK

2 University of Southern California, Sacramento, USA

3 University of Roehampton, London, UK 


\section{Introduction}

Recent research has documented the emergence of heterosexual men kissing each other in public settings, while still maintaining heterosexual social identities (Anderson et al. 2012a, b; Drummond et al. 2014). Heterosexual same-sex kissing between men is most prevalent in the United Kingdom, with lower prevalence rates in Australia. In both studies, it was argued that a decrease in cultural homophobia had enabled men to kiss each other without social censure. There is no empirical examination of the extent to which heterosexual men in the U.S. are kissing each other, even though the liberalization of attitudes toward gay people found in the U.K. and Australia is also present in the U.S. (Keleher and Smith 2012; Loftus 2001; Twenge et al. 2016), albeit to a lesser extent than the U.K. (Clements and Field 2014).

Given this trend of heterosexual men kissing each other in other countries (Anderson et al. 2012a, b; Drummond et al. 2014), we assess the prevalence of same-sex kissing behavior among heterosexual young men in the U.S. in this article. We utilize a mixed-method study of 442 quantitative surveys and 75 in-depth interviews among a racially diverse group of male participants from 11 universities in order to understand the frequency, context and meanings of same-sex kissing. We found that $40 \%$ of participants had kissed another man on the cheek and $10 \%$ on the lips. Both types of kisses were generally described as non-sexual expressions of affection, occurred between friends in a range of contexts, and were predicted by positive attitudes toward gay men. Thus, we contend that samesex kissing occurred in a greater range of contexts than previously found. We situate these findings within masculinities theory and the meanings associated with heterosexual masculinity in U.S. culture.

\section{Literature Review}

\section{The Censure of Same-Sex Kissing Between Heterosexual Men}

Central to the study of men and masculinities is the recognition that many men gain social privilege from their gender (Carrigan et al. 1985). These benefits are unevenly distributed, with white, heterosexual middle-class men gaining the most benefits as a group. However, also fundamental to this framework of masculinities is the notion that even this group of men suffer both physically and psychologically from the social dynamics of masculinities (Addis et al. 2010; Mahalik et al. 2007). For example, homophobia has been used to regulate heterosexual men's emotional (Monroe et al. 1997; Way 2011) and physical intimacy with each other (Derlega et al. 1989). Behaviors that are coded as sexual, including same-sex kissing between men (Floyd 2000), are particularly stigmatized in this context.

Social norms related to traditional forms of masculinities encourage men to put their health at risk (Courtenay 2000), and stigmatize behaviors that have been 
associated with positive mental and emotional health (Way 2011). Emotional expressionism, intellectual endeavor, physical tactility and exhibiting caring behaviors are all stigmatized due to their association with femininity (Plummer 1999). This 'antifeminity mandate' (Vandello and Bosson 2013: 102) is pervasive, and the conceptualization of masculinity as the absence of femininity has been a consistent research finding (e.g. Bosson et al. 2005; Kierski and Blazina 2009; McCreary 1994).

However, the stigmatization of femininity is also a factor in the explicit rejection of same-sex desire from masculinity for heterosexual and closeted gay men. This is because sexuality and gender are conflated in the U.S. (Schwartz and Rutter 1998), such that the presence of feminine behaviors in men is deemed indicative of being gay and any same-sex desire thus questions masculinity. This stigmatization of gay people has been so extreme that any individual act socially coded as 'gay' has traditionally been used to marginalize a person as having a stigmatized gay identity, regardless of their orientation, behavior and identity (McCreary 1994). This has been particularly prevalent during adolescence, and at schools (Epstein 1997; Plummer 1999).

Anderson (2008a) conceptualized this conflation of a socially coded "gay" behavior with a gay identity as the "one-time rule of homosexuality." Drawing on Harris's (1964) notion of the one-drop rule of race, the rule holds that any single act of samesex intimacy can cause the participant to be socially labeled as gay. For example, Floyd (2000) highlights how homophobia was deployed by men when they hugged, but this was dependent on its configuration of the hug and whether it was perceived to intimate same-sex desire. Yet this one-time rule only applies to same-sex interactions: As Schwartz and Rutter (1998: 12) write, it is "as if one drop of homosexuality tells the truth of self while one drop of heterosexuality in a homosexual life means nothing." So intense was this rule in the homophobic 1980s that two heterosexual men participating in non-sexual same-sex kissing would normally result in them being socially perceived as gay (Anderson 2008a; Derlega et al. 1989), unless it occurred in particular heteromasculine and homophobic contexts that were deemed to expunge any sexual desire.

This stigmatization of same-sex kissing means that it has been erased from many arenas of men's public lives (Connell 1995; Kimmel 1994). However, it also speaks to the historical and social context of masculinity. It has been possible, for example, for heterosexual men to kiss in particular contexts in the U.S., such as at sports events and when drunk (see Anderson et al. 2012a, b), and between father and son. Similarly, certain kinds of same-sex kissing between men are neither stigmatized nor indicative of gay identity in homophobic countries like Iran (see Anderson 2009), where kissing is part of a ritualized greeting behavior. In order to understand the operationalization of homophobia in policing gender in the U.S. context, it is necessary to theorize the links between homophobia and masculinity.

\section{Theoretical Framework}

Homophobia was a core dynamic of the social organization of masculinities in the late 20th century (Connell 1995; Floyd 2000; Plummer 1999). While this scholarship on men and masculinities at the time powerfully captured the ways in which 
homophobia was used to police and stratify masculinities, the cultural context of pervasive homophobia in the 1980s and early 1990s (Loftus 2001) meant that there was little recognition that this homophobic version of masculinity was specific to that period. Contemporaneous research did not explain how homophobia regulated men's behaviors in some homophobic countries (e.g. U.S.) but not others (e.g. Iran).

Anderson (2009) developed the concept homohysteria to understand the social conditions necessary for homophobia to regulate gendered behaviors. Defined as the fear of being socially perceived as gay, there are three factors that determine the level of homohysteria in a culture (McCormack and Anderson 2014). For a culture to be homohysteric, there must be: (1) recognition in that culture that same-sex desire exists as a static sexual orientation within a significant portion of the population; (2) high levels of attitudinal homophobia; (3) a conflation of gender and sexuality such that femininity in men is equated with a gay identity. When these conditions are met, homophobia serves as an effective mechanism to socially regulate masculinities (McCormack and Anderson 2014). Homohysteria enables recognition of the different ways in which homophobia is operationalized in specific contexts, giving greater understanding of the dynamics of those cultures.

McCormack and Anderson (2014) developed a stage model of homohysteria rooted in research on masculinities in the U.S. since the late $1800 \mathrm{~s}$. They argue that three stages exist: (a) homoerasure (1880s-1970s); (b) homohysteria (1970s-1990s); (c) inclusivity (1990s-). In the stage of homoerasure, gendered behaviors were not regulated by homophobia because it was not recognized that men could be gay. Here, there were homophobic laws and condemnation of same-sex sexuality, yet men exhibited physical and emotional intimacy (see Ibson 2002). These cultures were homophobic but not homohysteric.

A combination of social factors led to an upsurge in homophobic attitudes in the $1980 \mathrm{~s}$. High levels of homophobia occurred for three reasons: (1) HIV/AIDs became synonymous with gay identity and was labelled the 'gay plague' in a way that resulted in an upsurge of antigay violence and homophobia (Ruel and Campbell 2006); (2) there was a growth in homophobic religious beliefs, with fundamentalist Christianity gaining increasing political sway (Loftus 2001); and (3) the Republican party used fear of AIDS to create a moral panic around gay people (Lugg 1998). It was in this homohysteric culture that hypermasculine gendered displays predominated (Connell 1995).

The third stage is one of inclusivity. McCormack and Anderson (2014: 154) define this as "a culture where people with positive attitudes toward homosexuality are in the majority, and where there is widespread recognition of homosexuality as a sexual identity" (see also Dean 2014). It does not mean inclusivity of all difference, nor does it suggest that heteronormativity and heterosexual privilege have disappeared. The focus, instead, is on how such cultures have transitioned away from homohysteria.

The key driver for the decline in homohysteria is the improving attitudes toward gay people (McCormack and Anderson 2014). There is evidence of liberalizing attitudes toward gay people in the U.S. (Keleher and Smith 2012; Twenge et al., 2016): General Social Survey (GSS) data show the proportion of the U.S. population condemning same-sex sexuality has steadily declined since 1987. In 
a statistical analysis of these data, Keleher and Smith (2012: 1232) contend that "willingness to accept lesbians and gays has grown enormously since 1990." While more progressive attitudes toward gay people are partly due to generational replacement (Loftus 2001; Keleher and Smith (2012: 1324) show that all demographic groups analyzed became more tolerant; arguing that "we are witnessing a sweeping change in attitudes toward lesbians and gay men." There is also evidence of a generational effect, with younger people having more positive attitudes (Anderson and McCormack 2016). While the precise year the U.S. entered a stage of inclusivity related to homohysteria is questionable, it is clear that homophobia had significantly decreased by the mid-1990s (Dean 2014; Ghaziani 2014; McCormack and Anderson 2014).

In a national survey, almost $100 \%$ of heterosexuals supported legal equality for gays and lesbians (Doan et al. 2014). Fifty-five percent of participants also approved of gay men kissing on the cheek in public. The support for public displays of affection between gay couples occurs alongside a softening of masculinity among heterosexual men (Adams 2011; Haltom and Worthen 2014). Barrett (2013) documented the importance of bodily touch in friendships between gay and heterosexual men, and hugging and cuddling is present in U.S. high schools (Anderson 2014). Young men increasingly value emotional support and tactility as integral components of close friendships (McCormack 2011), even labelling these friendships bromances (Robinson et al. 2018).

However, there has not been any research about the prevalence of heterosexual young men engaging in same-sex kissing in the U.S. This is despite research showing same-sex kissing occurring between heterosexual male students in the U.K. and Australia. Indeed, short interviews conducted at two British universities found that $89 \%$ of heterosexual men reported kissing their heterosexual male friends on the lips, with half reporting that they would kiss a gay male friend in a similar fashion (Anderson et al. 2012a, b). In a replication using interview data from 90 heterosexual Australian undergraduate men, 29\% reported kissing their heterosexual male friends on the lips (Drummond et al. 2014).

The current study explores the prevalence and meanings associated with kissing between heterosexual men in the U.S. Research on men in university cultures in the U.S. (e.g. Adams 2011; Anderson 2008b) has found cultures of homosocial tactility and intimacy, similar to but less pronounced than in the U.K. (Anderson 2014; Anderson et al. 2012a, b). Given that attitudinal data shows the U.K. is more accepting of homosexuality than the U.S. (Anderson and McCormack 2016), it is possible that rates of kissing between men in the U.S. are lower than the U.K., research is needed to explore the prevalence of kissing in the U.S. and reasons why men engage in these behaviors. As such, our research questions are:

R1 What is the prevalence of kissing between heterosexual men in universities in the U.S.?

R2 What are the general attitudes toward homosexuality of the participants?

R3 How do rates of kissing correlate with fraternal affiliations?

R4 What are the reasons given for not kissing other men? 


\section{Methods}

This research uses a mixed-methods design to investigate the frequency and meanings of heterosexual young men kissing in the U.S. To examine prevalence, we surveyed university students located in the Southern, Eastern, and Western regions of the U.S., including those located in both liberal and conservative states. Three universities had religious affiliations (Christian), although none had compulsory religious education. We utilized 442 surveys from undergraduate heterosexual men across 11 geographically diverse U.S. universities during the 2011-2012 academic year: 4 universities were located in States in the West, 4 in the East, and 3 in the South. We undertook 40 surveys at 10 institutions, and 42 at one institution.

We then added 75 in-depth, semi-structured interviews. We interviewed seven participants at nine of the universities, and 6 at the remaining two. These universities were the same institutions as those where the surveys were collected. Participants ranged in age from 18-25 years old, fewer than half (43\%) belonged to a sport team or fraternity, and $37 \%$ were White (39\% Asian, 12\% Hispanic/Latino, 4\% Black, $8 \%$ other). No other demographic information was collected. These interview participants were paid $\$ 20$ for their participation.

\section{Survey Procedure}

We utilized two methods for recruiting participants for the survey. First, two White male undergraduate research assistants recruited 40 undergraduate participants from populated areas (e.g., near a food court) within each of eight universities (3 from the West, 3 from the East and 2 from the South). The same two research assistants undertook this work at all universities. Every third male who passed the research assistants was asked to participate in a brief, anonymous study. We approached every third male to avoid bunching and selecting multiple men from the same friendship group. Interested participants were verbally asked their age, sexual orientation (by how they identify), racial identity, and fraternal or sporting affiliation. Only those who identified as heterosexual, undergraduate students and between the ages of 18 and 25 were invited to continue the study. We restricted the age range of 18-25 as this corresponds with Arnett's (2004) notion of emerging adulthood.

In the second approach to survey data collection, we recruited students from three general education courses at one Western $(n=40)$, one Southern $(n=40)$, and one Eastern $(n=42)$ university. At these institutions we did not recruit participants through the first method. These surveys were completed during participants' regularly scheduled class time. This approach enabled us to collect data from students who do not readily put themselves forward for research (i.e. those recruited using the first method). We gained access to these classrooms through professional contacts at each university.

In total, 442 people took the survey (40 participants each at 10 universities, and 42 participants at one university). Eligible participants were briefly informed about research findings concerning heterosexual men kissing in the United Kingdom and 
Table 1 Survey Questions

1 In total, how many different male friends have you kissed on the cheek (it counts if they kissed you, too)?

2 In total, how many different male friends have you kissed on the lips (it counts if they kissed you, too)? This kiss can be done for any reason including a bet, a dare, a drinking game, or for sexual pleasure

3 What percentage of the time are you drunk when giving or getting a kiss from another man on the lips?

4 How many times have you made out (sustained kissing) with another man, for any reason (including as a joke or dare?)

5 How many different straight men have you cuddled on the sofa or spooned with in bed for less than $5 \min$ ?

6 How many different straight men have you cuddled on the sofa or spooned with in bed for more than 5 min?

7 If you have never kissed, cuddled, or spooned with another man, have you ever wanted to but stopped yourself?

8 How many gay or bisexual male friends do you have?

9 If a gay or bisexual man was part of your close friendship group, would you be comfortable kissing him on the lips?

10 If a gay or bisexual man was part of your close friendship group, would you be comfortable making out with him, even as a joke?

11 Would you be comfortable cuddling or spooning with a gay or bisexual male for any duration of time?

12 How many men of any sexual orientation have you given a brief kiss to out of experimentation, your own sexual desire, or in a threesome?

13 How many men of any sexual orientation have you made out with out of experimentation, your own sexual desire, or in a threesome?

Australia and were told that they would be asked questions to ascertain what was occurring in the United States. After hearing this information, participants were asked 'what is your attitude to gay men,' and given a 4-point rating scale ( $1=$ Entirely Negative, $2=$ somewhat negative, $3=$ somewhat positive, $4=$ Entirely Positive $)$. We determined that neutral would be a confusing response, so eliminated that as a choice. This is not intended as a nuanced tool for understanding attitudes toward gay men, but as a method of understanding a person's general attitude toward gay men.

Next, participants responded to 13 short questions related to kissing men on the cheek and lips (see Table 1). Importantly, "kissing" was not defined for participants; rather, they made use of their own definitions, and we did not differentiate between kisses that were active (i.e. the person instigated the kiss) or passive (i.e. the person received the kiss). This open definition reflects the personal and contextualized nature of intimate behaviors.

\section{Interview Procedure}

We augmented survey responses with 75 in-depth, semi-structured interviews lasting an average of $45 \mathrm{~min}$ each. These interviews reflected the same themes as the 
short survey, but the semi-structured interview processes facilitated for open discussions about the reasons as to why men do or do not kiss, and the mechanics and meanings of said kisses. The participants were obtained by having the two White male undergraduate research assistants standing in populated areas of each of the 11 universities. They asked passing male students if they wished to earn $\$ 20$ by participating in a one hour interview for academic research. Interested individuals received an information sheet about the study. In order to prevent repetition, we only interviewed men who had not filled out the survey.

The two research assistants conducted the interviews, and briefly described previous research finding kissing occurring in the UK and Australia - that such behaviors existed, and the contexts in which these kisses tended to occur. We carefully considered the effect of demand characteristics such as social desirability bias on participant response (Orne 1962), but concluded that describing previous findings regarding same-sex kissing to participants was more favorable than concealing the nature of the study because it reduced participant speculation that we were screening them for covert same-sex desire. While it remains possible that demand characteristics affected participants' responses, we feel that the continued desire of heterosexuals to be labeled as heterosexual makes it unlikely that they would have reported kissing another man if in fact they had not.

\section{Analysis}

We analyzed responses to the short surveys in several ways. First, we examined participants' self-reported attitudes toward gay men and the number of gay male friends they had in order to understand their pre-existing attitudes towards gay people. We then examined basic frequencies of same-sex kissing (i.e., kissing on the cheek, kissing on the lips). We noted that both indices of same-sex kissing were positively skewed, so we applied a Box-Cox transformation to normalize the data prior to significance testing. We then explored several predictors of same-sex kissing, including Attitudes Toward Gay Men ( $1=$ Entirely Negative to $4=$ Entirely Positive), Membership in a Fraternal Organization $(0=$ No, $1=$ Yes), and Number of Gay Friends (continuous). The data were nested hierarchically: multiple students participating from each university, so we tested our quantitative hypotheses using multilevel regression equations (Generalized Estimating Equations (GEEs); Zeger and Liang 1986) to account for within-subject dependencies. In all GEE models, continuous predictors were mean-centered and dichotomous predictors were effect-coded prior to testing. We report the results of these models in terms of unstandardized regression coefficients $(B \mathrm{~s})$ and Wald zs. Unstandardized regression coefficients represent measures of effect size, indicating that a one-unit increase in the predictor variable is associated with a $B$-unit increase in the outcome variable.

Then, using a constant-comparative method of open and axial coding, we examined the qualitative data gained from in-depth interviews. Following initial coding, we compared $10 \%$ of the transcriptions for inter-rater reliability discrepancies (IRR.85). We acknowledge that this coding was based on an interpretive framework; 
however, we contend that the rigor of our interpretive inquiry and the richness of our descriptions lend credibility to the analysis (Gubrium and Holstein 1997).

\section{Ethics}

The 75 interviewees provided written consent, but the human subject's approval board of the home institution determined that oral consent was sufficient for surveys. The panel maintained it unnecessary to retain written documentation from participants. The ethical review boards of all universities we sampled concurred. Thus, survey participants provided oral consent and we followed all ethical procedures of the American Sociological Association's guidelines for both sets of participants, including anonymity and right to withdraw without penalty.

\section{Results}

\section{Prevalence of Heterosexual Men Who Kiss other Men}

One of our primary research questions is the prevalence of same-sex kissing among straight men in this U.S. sample. Descriptive survey data revealed that $38 \%$ of the 442 heterosexual men reported having kissed another man on the cheek and $9 \%$ on the lips. There was substantial variability in the frequency of these behaviors, with the number of cheek kisses for each participant ranging from 0 to 30 , and the number of lip kisses ranging from 0 to 5 . To get an overall sense of whether the men in this sample were kissing other men, we conducted one-sample $t$-tests comparing the average number of cheek and lip kisses to a null value of zero. As expected, mean levels of kissing were significantly greater than 0 for the cheek, $t(442)=15.44$, $p<0.001$, and for the lips, $t(439)=6.26, p<0.001$.

We noted slight differences in rates of reported kissing between the surveys and the in-depth interviews. $9 \%$ of heterosexual men reported kissing or being kissed by another man on the lips in surveys, whereas $13 \%$ reported kissing in the interviews. A similar trend emerged for reports of kissing on the cheek: $38 \%$ of those surveyed indicated that they had kissed or been kissed on the cheek by a heterosexual male friend, compared to $53 \%$ of those undergoing in-depth interviews. Averaging across the two methodologies, $10 \%$ of self-identified heterosexual undergraduate men in our sample reported kissing or being kissed by another man on the lips, and $40 \%$ reported kissing or being kissed by another man on the cheek.

\section{Attitudes Towards Gay Men}

We examined participants' feelings toward gay men in terms of explicit attitude ratings and self-reported number of gay friends. To begin, we conducted a one-sample $t$ test on mean ratings of attitudes toward gay men, comparing the mean to the midpoint of the scale to determine whether participants' attitudes were generally positive or negative. The mean rating of attitudes toward gay men was significantly 
above the midpoint of the scale $(M=3.11, S D=0.88, t(409)=13.66, p<0.001)$, indicating that participants reported relatively favorable attitudes toward gay men. Descriptively, $74 \%$ of participants reported 'somewhat positive' or 'entirely positive' attitudes toward gay men. Furthermore, participants in this sample had an average of more than four gay friends $(M=4.25, S D=11.31)$, with $80 \%$ of the sample reporting at least one gay friend. It seemed likely that the variables tapping explicit attitudes toward gay men and total number of gay friends were closely related, such that participants who had more gay friends probably had more favorable attitudes toward gay men. To test this hypothesis, we regressed Attitudes Toward Gay Men onto Number of Gay Friends. As expected, participants who reported having more gay friends reported marginally more favorable attitudes toward gay men in general, $B=0.0029, S E=0.0017, z=1.73, p=0.084$.

Data from in-depth interviews confirmed these findings. Of the 75 men interviewed, only one offered disparaging remarks about gay men, and two reported too little contact with gay men to draw strong conclusions. Conversely, unlike heterosexual men of the previous generation (Plummer 1999), most men maintained friendships with gay men.

There was evidence that social contact with gay men promoted inclusivity toward gay men for these participants (see Pettigrew 2008). Corey said, "I have lots of gay friends. In fact the closet friend I have is Gabriel, and he's gay... I share everything with him." Rob even grew emotional when discussing his gay male friend:

I was at a party my freshman year, sitting talking to one of my close gay guy friends and I told him my whole life story, including some bad stuff that happened in the past. After, I said to him 'the support you show me is why I will always support gay rights. I want to stand up and be counted.'

Six of the 75 men interviewed said that their best friend or a close friend was gay. This type of positive social interaction among gay and heterosexual men occurred even on conservative campuses. Charles, who we interviewed at a small, politically conservative campus in the American South, said:

Me and Austin have roomed together in college for the past 2 years. I don't really see him as 'gay' anymore. I kind of forget that some people might think it's strange that we share a room. I'd never swap him for anyone though.

\section{Contextualizing Kissing}

Previous work in the U.K. (Anderson et al. 2012a, b) and Australia (Drummond et al. 2014) found that homosocial kissing occurred at higher rates among men who: (1) were involved with either a fraternity or an all-male competitive sport; (2) had more positive attitudes toward gay people; and (3) consumed alcohol. We sought to replicate and extend these findings to undergraduates in the U.S.

To explore links between fraternal affiliations and same-sex kissing, we regressed both of the kissing variables (cheek and lips) individually onto Membership in a Fraternal Organization. Compared to men who were not in a fraternal organization, those who were in a fraternal organization reported significantly more kissing on 
the lips, $B=0.007, S E=0.003, z=2.29, p=0.022$, but not on the cheek, $B=0.008$, $S E=0.006, z=1.35, p=0.178$.

The increased rate of homosocial kissing among members of fraternal or sports organizations was something that participants also noted during interviews. Evidencing this, Jordan said, "I guess I see it [same-sex kissing] much more between men on the sports teams; I mean everyone knows that they do that kind of thing." Derek agreed, saying, "A few of the guys in the frat have been known to kiss each other when drunk, it's become pretty normal now. We all know who the kissers are! [laughs]" Alan also identified the normalcy of same-sex kissing in sport teams and on fraternities: "After scoring a goal it's kinda expected that you'll receive a lot of high fives, hugs and maybe a kiss."

We then tested whether participants' broader attitudes toward gay men were associated with reports of same-sex kissing by regressing both of the kissing variables (cheek and lips) individually onto Attitudes Toward Gay Men. Compared to participants with less favorable attitudes toward gay men, those with more favorable attitudes toward gay men reported significantly more kissing on the cheek, $B=0.008$, $S E=0.002, z=5.21, p<0.001$, and marginally more kissing on the lips, $B=0.007$, $S E=0.004, z=1.82, p=0.069$.

Interviews with men who kissed other men explained that this form of tactility was an expression of affection for a close friend (see also Anderson et al. 2012a, b). University men often kissed in public venues like dance clubs and house parties. Tom, a biology student at a university located in the American South, said, "Me and my friend were drinking and dancing in a bar and we kissed on the lips. It was just in the moment of ecstasy. It's not really an issue in these kinds of places." Exemplifying the possible influence of alcohol on cross-cultural rates of kissing (see Peralta 2007), survey participants who reported having kissed another man on the lips indicated that this behavior occurred in the context of alcohol about $10 \%$ of the time $(M=10.29, S D=28.44)$. While similar effects have not been quantified in other research, alcohol consumption emerged as a dominant theme in British men's kissing narratives (see Anderson et al. 2012a, b]).

Alex, a computer science student from the Midwest, agreed. "You don't really see it on the college campus. It's more in the bars and clubs we frequent. But I've been kissed by enough guys on nights out to know that it happens!" Pat, enrolled in a university on the West Coast, shared similar experiences, "Just before I took the first shot on my birthday one of my friends gave me a kiss on the cheek, so I grabbed his face and kissed him back."

Participants in our study stated that they did not consider their kissing a sexual act. Instead, participants likened these brief kisses to a strong embrace and described it as a demonstration of affection for a close friend in particular contexts. Highlighting this, when asked about why he kisses his friend, one participant said, "I kiss him because I love him. I'm not attracted to him like that, but I do love him." And when another was asked about who is worthy of being kissed, he said, "I guess just my really close friends, the guys I'm closest to."

Kisses occurred in various locations, but most often in public spaces like bars, dance clubs, and fraternity parties. Alcohol was frequently involved but not always. A few of the participants suggested that they kissed a friend in a private space, such 
as a dorm room, but this was exceptionally rare. Still, when asked if the kisses were performed any different in private, no participant indicated that they were. James said, "It doesn't matter where you kiss him, the point is you're doing it to show your love."

Thus, our U.S. sample contextualized same-sex kissing as associated with membership in a fraternal organization, having positive attitudes toward gay men in general, and alcohol consumption away from campus. These acts were not described as sexual or romantic in nature, framed instead as expressions of friendly affection. These findings provide a framework for understanding how, when, and why heterosexual men choose to engage in tactile behaviors with one another.

\section{Men Who do Not Kiss Other Men}

In addition to examining prevalence and context of same-sex kissing among young men in the U.S., we also investigated the reasons why men did not kiss other men. Analysis of interview data highlighted three themes: (1) kissing is reserved for romantic relationships only; (2) heterosexual men do not kiss other men; and (3) kissing another man is associated with being gay.

The predominant reason that men gave for not kissing another man is that they view kissing as something that should be reserved only for sexual relationships. One participant from the Midwest said,

I consider it to be an intimate thing, something I'd only do with a significant other. That crosses boundaries that aren't anything to do with gay. I wouldn't even do it with a female friend because that'd just be weird.

Another participant said, "The lips is a little weird. It's too personal for me, something saved for a girlfriend. Most of my friends would be the same. It wouldn't start a fight but it wouldn't be acceptable." A participant from the West said, "I don't mind kissing guys on the cheek when playing sports, like after we win or something, but on the lips is more a thing that should be kept for my girlfriend." Another participant who had never kissed a male friend added, "It's not that I'm against it. It's just not for me. Kissing anyone [casually], even a girl, it's just not who I am." For these participants, kissing remained a sexual endeavor.

Others remarked that they do not engage in same-sex kissing because they had no desire to do so. When pressed for details, one participant articulated that, "...it's just not part of our culture." Another said, "It's fine that they do that in England, but guys just don't do that here."

Five of the undergraduates $(7 \%)$ expressed that they do not kiss other men because they associated it with gay identity. One student said, "Kissing [guys] on the lips is more towards homosexual or the gay place, and I'm not gay so I don't like doing that. I don't enjoy that." Another participant, who said he kisses male friends on the cheeks but not the lips, said, "It's too gay for me." Three other men said that they feared that being kissed or kissing another guy might compromise their heterosexual identity. These three men espoused a more aggressive disposition, one said, "I'm not gay. That shit isn't for me." This may be evidence of personal homohysteria 
for these participants, but it could also be because kissing is coded as a form of sexual desire rather than homosocial (non-sexual) intimacy. Nonetheless, $89 \%$ of the men we interviewed did not discuss either personal or social regulation of masculinity related to same-sex kissing. This suggests, at least indirectly, that homohysteria was not a particularly strong reason for heterosexual men to avoid same-sex kissing contact with one another.

\section{Discussion}

This study examined the prevalence and rationales for same-sex kissing among university-attending young men across the U.S. Given research that found a new trend of heterosexual men kissing each other (Anderson et al. 2012a, b; Drummond et al. 2014), we examined both the prevalence of same-sex kissing among young adult males in the U.S. and the rationales of this behavior. Overall, $40 \%$ of the self-identified heterosexual undergraduate men in our sample reported kissing or being kissed by a male friend on the cheek, while $10 \%$ reported kissing or being kissed by a male friend on the lips. This compares with $89 \%$ of men in the U.K. study who report having kissed another man on the lip (Anderson et al. 2012a, b). ${ }^{1}$ Despite overall kissing rates varying across universities, our statistical models accounted for the fact that observations were nested within universities. Thus, our estimates refer to the sample at large, demonstrating that this form of kissing occurs across these 11 universities that positioned in different areas of the country and hold diverse student populations.

While same-sex kisses could be viewed as sexual exploration, the narratives of participants suggest that kissing does not have sexual connotations for these men. They described it as a form of social bonding, and a way of demonstrating close friendship. Corroborating international scholarship on men's kissing behaviors (Anderson et al. 2012a, b; Drummond et al. 2014), same-sex kissing among heterosexual undergraduate men appears to be an act of emotional expression, and not sexual fluidity. In the sample of 75 men interviewed, five participants said that same-sex kissing would connote a gay identity $-7 \%$ of that sample. Thus, while heterosexual men kissing one another may not be as widespread as in the U.K. or Australia, it is similarly a socially acceptable behavior amongst participants in this study (c.f. Derlega et al. 1989; Floyd 2000).

The emergence of heterosexual men kissing documented in this study has important implications for theoretical understandings of masculinity in the U.S. While limited in prevalence, these behaviors provide a challenge to orthodox forms of masculinity that marginalize behaviors associated with femininity or gay identity (Connell 1995; Plummer 1999). Whereas articulations of masculinity during periods of homohysteria do not permit heterosexual men to engage in intimate behaviors with other men (Kimmel 1996; Plummer 1999), a great deal more flexibility is afforded to participants in this study who do not see kissing another man as a threat to their

1 The U.K. study did not examine cheek-kissing so comparison is not available. 
heterosexual social identity. With participants espousing positive attitudes toward gay people (see also Twenge et al. 2016), and engaging in feminized behaviors such as kissing without censure, this study supports the growing body of literature that discusses the emergence of inclusive masculinities (e.g. Anderson 2014; McCormack 2012; Gottzen and Kremer-Sadlik 2012). Expanding recent research showing that some men engage in same-sex sex while maintaining heterosexual identities (McCormack 2018; Vrangalova and Savin-Williams 2013), this study highlights that kissing is not necessarily sexual and can be coded as an emotional, bonding experience.

The data does not enable an understanding of other men's perceptions of kissing behaviors - as such, it is possible that these men are perceived as gay by others, and that the one-time rule of homosexuality still exists more generally. This is an important factor in guarding against too broad interpretations from these results. We also highlight that participants had the opportunity in these semi-structured interviews to discuss impediments to same-sex kissing and social issues around it: only five of the participants discussed maintenance of a heterosexual identity as a reason for avoiding kissing. Thus, even if others still perceive participants to be gay for kissing, it would seem that such perception has lost its ability to police other men's behaviors and expressions of emotional intimacy for me in our sample (Anderson et al. 2012a, b; c.f. Plummer 1999).

This study develops the growing body of research on inclusive masculinities in several ways. Firstly, by providing quantitative evidence of the emergence of samesex kissing among undergraduate heterosexual men, it demonstrates the extent to which a once-censured form of tactility is present among men in the U.S. It also corresponds with research demonstrating the increasing range of homosocial behaviors that inclusive straight men engage in (e.g. Anderson and McCormack 2015; Scoats 2017). While not the main focus of the study, the positive attitudes toward homosexuality and gay men found among almost three quarters of the sample population is further evidence of the social trend of decreasing homophobia, particularly given the random sampling procedure at 11 different universities across the U.S. As such, this research supports the argument that dominant forms of masculinities in U.S. university cultures are transitioning away from a homophobic jock figure, where homosexuality was exceedingly stigmatized (as explained by Connell's (1995) theorizing), to a set of masculinities that are inclusive both of same-sex sexual desires and non-sexual displays of intimacy between male friends (Anderson 2014; Scoats et al. 2018).

This study also enables comparison of levels of kissing with other Western cultures, namely the U.K. (Anderson et al. 2012a, b) and Australia (Drummond et al. 2014). We contend that it is the differences in attitudes toward gay people in these cultures that are the primary reason for the cross-cultural differences in kissing (see Anderson 2014). However, structural variance in access to alcohol is also likely a contributing factor. Given that alcohol acts as a disinhibitor that escalates emotional expression, the more liberal drinking laws in the U.K. and Australia (where drinking is permitted at 18) and on university campuses, may result in more tactile gendered behaviors in these contexts. Importanaly, while Peralta (2007) showed how alcohol consumption led men to engage in a number of damaging masculine behaviors, our 
research found that alcohol may facilitate less harmful masculine behaviors in particular social contexts.

Age and social context are likely to be important factors in this finding. In contemporary research, kissing has only been demonstrated among younger men, and it is argued that youth culture is an important context in which these behaviors occur (Anderson 2014). The developmental stage of 'emerging adulthood' (Arnett 2004), in which these young men are currently situated, likely provides the space to explore same-sex kissing with heterosexual friends. In addition to being a period in life where it is possible to bond closely with other young men (Kimmel 2008), the social context of decreased homophobia means that men are less likely to be regulated if they engage in such behaviors (Anderson et al. 2012a, b).

The association between membership of a fraternity or sports team and same-sex kissing may be attributed to the heteromasculine capital afforded to men in these organizations. When masculine capital is elevated, men are afforded more space for gender transgression without being labelled as gay (McGuffey and Rich 1999). However, given that fear of being socially perceived as gay was only the third stated reason for not wanting to kiss other men, the link with fraternal organizations is likely more attributable to the way these institutions structure men to spend increased time socializing together and where close friendships can form. It is in these contexts that 'bromances' between friends are more likely to occur and in which homosocial friendships are often privileged (Robinson et al. 2018), and that homosocial spaces such as fraternities may facilitate exploration of such intimacy.

Comparing these findings with women's same-sex kisses in university contexts is a useful endeavor. Rupp et al. (2014) argue that the college hook up scene is a gendered and heteronormative sexual field that fosters the practice of women kissing other women in public for the benefit of male onlookers, rather than because of same-sex sexual desire-even though women's sexual desires have been shown to be quite fluid (Diamond 2008). While they contend that these kisses are primarily for men's benefits, they also provide new perspectives on how kisses are perceived socially, arguing that as their participants "act in ways that uncouple desire, behavior, and identity from heteronormativity, they are participating in the process of undoing gender" (Rupp et al. 2014: 229). They discuss how these same-sex kisses serve to undo gender and act in ways that subvert dominant binary categorizations of sex and sexuality. In a similar manner, while further research will need to interrogate how men's kissing behaviors are determined by institutional context and masculine capital, they can also be interpreted as a mechanism by which norms of orthodox masculinities are subverted and the one-time rule of homosexuality undermined.

\section{Limitations and Future Directions}

There are of course limitations to this study. Social desirability bias may have affected participants' responses, and it is possible that some interview participants identified as straight rather than admit being gay to another man. Our findings are also restricted to college-attending heterosexual men. While we recruited participants from a diverse range of geographical and institutional settings, data 
is a long way from reflecting the cultural diversity of the U.S. Similarly, while our population is diverse in terms of race, we have not provided detailed analysis of this variable in this article. Findings may also have been influenced by the position of the researcher in the field, and the role of social desirability in participant responses.

There were also differences in percentage across surveys and interview, with higher rates of reported kissing found among interview respondents compared to survey respondents (13\% rather than 9\% for kissing, and 53\% rather than $38 \%$ for cheek kissing). One explanation for this is that people asked to disclose their sexuality to a stranger may be inclined to identify as straight rather than disclose a sexual minority identity - and as such, the survey results provide a more representative figure. However, we have argued elsewhere that it unlikely that participants would opt to convincingly maintain a false identity for the duration of an interview, rather than decide to terminate the interview (Anderson and McCormack 2016). These could also be attributed to differences in sample size; self-selection factor among men opting into a long interview; or that in-depth interviews permitted the researchers more clarity in expressing that they were not equating kissing behaviors with a closeted gay identity, making participants more willing to disclose instances of homosocial tactility. Regardless of the exact reason for these differences, it is clear from both in-depth interviews and short surveys that our participants reported homosocial kissing at rates greater than 0 . We refer to the average statistic for these reasons, and note that the differences between the average and the survey statistics are quite small.

We have restricted claims of generalizability to men attending colleges in the U.S. aged between 18 and 25 as this demographic may be one where same-sex kissing behaviors are more likely to apply. First, participants live in a life stage of emerging adulthood in which men have more freedom to engage in homosocial behaviors and develop deep friendships (Arnett 2004). The literature on same-sex kissing among men (Anderson et al. 2012a, b; Drummond et al. 2014) has only studied university-attending men and this is because the university is also a context where men are able to develop close friendships and may also be an institutional context for more liberal sexual cultures (Bogle 2008).

While both the survey and interviews distinguished between kissing on the cheek and lips, the focus on prevalence and situational contexts in which kissing occurred (e.g. fraternities, sports etc.) means that there is not the systematic data to present findings in this research on the ways in which these kinds of kisses occur in different contexts. Examining the different forms of kissing, the meanings attached to them and in what contexts they occur are important areas of future research. Furthermore, future research needs to examine for these behaviors when investigating college men's social lives, in both qualitative and quantitative investigations. Given that research has highlighted the performative nature of same-sex kissing for women in mix-sexed groups (Rupp et al. 2014), further research examining for differences in how straight men kiss each other in homosocial and mixed-sex contexts would also develop gendered and sociological understanding of these issues. 


\section{Conclusion}

This research provides a significant addition to empirical understanding of contemporary masculinities, showing that same-sex kissing between men is a behavior that can be engaged in while maintaining a heterosexual identity at these universities. It finds $10 \%$ of participants had kissed another man on the lips (R1); that participants exhibited positive attitudes toward homosexuality (R2); that same-sex kissing was positively correlated with fraternal affiliation (R3); and that reasons for not engaging in same-sex kissing related to kissing being reserved for romantic relationships, not appropriate for men, and associated with homosexuality (R4). The findings concerning positive attitudes toward gay men are consistent with other work suggesting that contemporary heterosexual undergraduate men have relatively positive explicit attitudes toward gay men (Woodford et al. 2012). We demonstrate that these attitudes are correlated with same-sex kissing behaviors. While occurrence is less than found in other Western countries (Anderson et al. 2012a, b; Drummond et al. 2014), we demonstrate that a proportion of men at these universities are able to engage in same-sex kissing without being regulated by their peers.

Acknowledgements This research was supported by the American Institute of Bisexuality.

\section{Compliance with Ethical Standards}

Conflict of interest All authors declares that they have no conflict of interest.

Ethical Approval All procedures performed in studies involving human participants were in accordance with the ethical standards of the institutional and/or national research committee and with the 1964 Helsinki declaration and its later amendments or comparable ethical standards.

Informed Consent Informed consent was obtained from all individual participants included in the study.

Open Access This article is distributed under the terms of the Creative Commons Attribution 4.0 International License (http://creativecommons.org/licenses/by/4.0/), which permits unrestricted use, distribution, and reproduction in any medium, provided you give appropriate credit to the original author(s) and the source, provide a link to the Creative Commons license, and indicate if changes were made.

\section{References}

Adams, A. (2011). "Josh wears pink cleats": Inclusive masculinity on the soccer field. Journal of Homosexuality, 58(5), 579-596.

Addis, M. E., Mansfield, A. K., \& Syzdek, M. R. (2010). Is "masculinity" a problem?: Framing the effects of gendered social learning in men. Psychology of Men and Masculinity, 11, 77-92.

Anderson, E. (2008a). "Being masculine is not about who you sleep with..." heterosexual athletes contesting masculinity and the one-time rule of homosexuality. Sex Roles, 58, 104-115.

Anderson, E. (2008b). Inclusive masculinity in a fraternal setting. Men and Masculinities, 10(5), 604-620.

Anderson, E. (2009). Inclusive masculinity: The changing nature of masculinities. London: Routledge. 
Anderson, E. (2014). 21st century jocks: Sporting men and contemporary heterosexuality. Basingstoke: Palgrave Macmillan.

Anderson, E., Adams, A., \& Rivers, I. (2012a). "I kiss them because I love them": The emergence of heterosexual men kissing in British institutes of education. Archives of Sexual Behavior, 41, 421-430.

Anderson, E., \& McCormack, M. (2015). Cuddling and spooning heteromasculinity and homosocial tactility among student-athletes. Men and Masculinities, 18, 214-230.

Anderson, E., \& McCormack, M. (2016). The changing dynamics of bisexual men's lives. New York: Springer.

Anderson, E., McCormack, M., \& Lee, H. (2012b). Male team sport hazing initiations in a culture of decreasing homohysteria. Journal of Adolescent Research, 27(4), 427-448.

Arnett, J. J. (2004). Emerging adulthood. New York: Oxford University Press.

Barrett, T. (2013). Friendships between men across sexual orientation: The importance of (others) being intolerant. The Journal of Men's Studies, 21, 62-77.

Bogle, K. (2008). Hooking up: Sex, dating and relationships on campus. New York: New York University Press.

Bosson, J. K., Prewitt-Freilino, J. L., \& Taylor, J. N. (2005). Role rigidity: A problem of identity misclassification? Journal of Personality and Social Psychology, 89(4), 552.

Carrigan, T., Connell, R., \& Lee, J. (1985). Toward a new sociology of masculinity. Theory and Society, 14, 551-604.

Clements, B., \& Field, C. D. (2014). Public opinion toward homosexuality and gay rights in Great Britain. Public Opinion Quarterly, 78, 523-547.

Connell, R. (1995). Masculinities. Berkley: University of California Press.

Courtenay, W. H. (2000). Constructions of masculinity and their influence on men's well-being: A theory of gender and health. Social Science and Medicine, 50, 1385-1401.

Dean, J. J. (2014). Straights. New York: New York University Press.

Derlega, V. J., Lewis, R. J., Harrison, S., Winstead, B. A., \& Costanza, R. (1989). Gender differences in the initiation and attribution of tactile intimacy. Journal of Nonverbal Behavior, 13, 83-96.

Diamond, L. (2008). Sexual fluidity: Understanding women's love and desire. Cambridge: Harvard University Press.

Doan, L., Loehr, A., \& Miller, L. R. (2014). Formal rights and informal privileges for same-sex couples: Evidence from a national survey experiment. American Sociological Review, 79, 1172-1195.

Drummond, M. J., Filiault, S. M., Anderson, Eric, \& Jeffries, D. (2014). Homosocial intimacy among Australian undergraduate men. Journal of Sociology, 51, 643-656.

Epstein, D. (1997). Boyz'own stories: Masculinities and sexualities in schools [1]. Gender and Education, 9, 105-116.

Floyd, K. (2000). Affectionate same-sex touch: The influence of homophobia on observers' perceptions. The Journal of Social Psychology, 140, 774-788.

Ghaziani, A. (2014). There goes the gayborhood?. Princeton: Princeton University Press.

Gottzén, L., \& Kremer-Sadlik, T. (2012). Fatherhood and youth sports a balancing act between care and expectations. Gender and Society, 26, 639-664.

Gubrium, J., \& Holstein, J. (1997). The new language of qualitative methods. London: Oxford University Press.

Haltom, T. M., \& Worthen, M. G. (2014). Male ballet dancers and their performances of heteromasculinity. Journal of College Student Development, 55, 757-778.

Ibson, J. (2002). Picturing men: A century of male relationships in everyday life. Washington, DC: Smithsonian Books.

Keleher, A., \& Smith, E. R. A. N. (2012). Growing support for gay and lesbian equality since 1990. Journal of Homosexuality, 59, 1307-1326.

Kierski, W., \& Blazina, C. (2009). The male fear of the feminine and its effects on counseling and psychotherapy. The Journal of Men's Studies, 17, 155-172.

Kimmel, M. S. (1994). Masculinity as homophobia: Fear, shame and silence in the construction of gender identity. In Harry Brod \& Micahel Kaufman (Eds.), Theorizing masculinities. Thousand Oaks: Sage.

Kimmel, M. S. (1996). Manhood in America. New York: Free Press.

Kimmel, M. S. (2008). Guyland. New York: Harper Collins.

Loftus, J. (2001). America's liberalization in attitudes toward homosexuality, 1973 to 1998. American Sociological Review, 66, 762-782. 
Lugg, C. A. (1998). The religious right and public education: The paranoid politics of homophobia. Educational Policy, 12, 267-283.

Mahalik, J. R., Burns, S. M., \& Syzdek, M. (2007). Masculinity and perceived normative health behaviors as predictors of men's health behaviors. Social Science and Medicine, 64, 2201-2209.

McCormack, M. (2011). Hierarchy without hegemony: Locating boys in an inclusive school setting. Sociological Perspectives, 54, 83-101.

McCormack, M. (2012). The declining significance of homophobia: How teenage boys are redefining masculinity and heterosexuality. Oxford: Oxford University Press.

McCormack, M. (2018). Mostly straights and the study of sexualities. Sexualities, 21, 3-15.

McCormack, M., \& Anderson, E. (2014). The influence of declining homophobia on men's gender in the United States: An argument for the study of homohysteria. Sex Roles, 71, 109-120.

McCreary, D. R. (1994). The male role and avoiding femininity. Sex Roles, 31, 517-531.

McGuffey, C. S., \& Rich, B. L. (1999). Playing in the gender transgression zone: Race, class, and hegemonic masculinity in middle childhood. Gender and Society, 13(5), 608-627.

Monroe, M., Baker, R. C., \& Roll, S. (1997). The relationship of homophobia to intimacy in heterosexual men. Journal of Homosexuality, 33, 23-37.

Orne, M. T. (1962). On the social psychology of the psychological experiment: With particular reference to demand characteristics and their implications. American Psychologist, 17, 776-783.

Peralta, R. L. (2007). College alcohol use and the embodiment of hegemonic masculinity among European American men. Sex Roles, 56(11-12), 741-756.

Pettigrew, T. F. (2008). Future directions for intergroup contact theory and research. International Journal of Intercultural Relations, 32, 187-199.

Plummer, D. (1999). One of the boys: Masculinity, homophobia, and modern manhood. London: Routledge.

Robinson, S., Anderson, E., \& White, A. (2018). The bromance: Undergraduate male friendships and the expansion of contemporary homosocial boundaries. Sex Roles, 78, 94-106.

Ruel, E., \& Campbell, R. T. (2006). Homophobia and HIV/AIDS: Attitude change in the face of an epidemic. Social Forces, 84, 2167-2178.

Rupp, L., Taylor, V., Regeg-Messalem, S., Fogarty, A., \& England, P. (2014). Queer women in the hookup scene: Beyond the closet? Gender and Society, 28, 212-235.

Savin-Williams, R. C., \& Vrangalova, Z. (2013). Mostly heterosexual as a distinct sexual orientation group: A systematic review of the empirical evidence. Developmental Review, 33, 58-88.

Schwartz, P., \& Rutter, V. (1998). The gender of sexuality. Walnut Creek: AltaMira Press.

Scoats, R. (2017). Inclusive masculinity and Facebook photographs among early emerging adults at a British University. Journal of Adolescent Research, 32(3), 323-345.

Scoats, R., Joseph, L. J., \& Anderson, E. (2018). 'I don't mind watching him cum': Heterosexual men, threesomes, and the erosion of the one-time rule of homosexuality. Sexualities, 21, 30-48.

Twenge, J. M., Sherman, R. A., \& Wells, B. E. (2016). Changes in American adults' reported same-sex sexual experiences and attitudes, 1973-2014. Archives of Sexual Behavior, 45(7), 1713-1730.

Vandello, J. A., \& Bosson, J. K. (2013). Hard won and easily lost: A review and synthesis of theory and research on precarious manhood. Psychology of Men and Masculinity, 14, 101-113.

Way, N. (2011). Deep secrets. New York: New York University Press.

Woodford, M. R., Silverschanz, P., Swank, E., Scherrer, K., \& Raiz, L. (2012). Predictors of heterosexual college students' attitudes toward LGBT people. Journal of LGBT Youth, 9, 297-320.

Zeger, S. L., \& Liang, K.-Y. (1986). Longitudinal data analysis for discrete and continuous outcomes. Biometrics, 42, 121-130. 